\title{
Sharing the podium: exploring the process of peer learning in professional conducting
}

\section{Brydie-Leigh Bartleet and Ralph Hultgren}

Queensland Conservatorium Griffith University, P 0 Box 3428, South Bank, QLD, 4101, Australia

b.bartleet@griffith.edu.au, r.hultgren@griffith.edu.au

We discuss a recent peer-learning project we undertook as co-conductors of the Young Conservatorium Wind Orchestra at Griffith University. Drawing on current educational theory on peer learning and material from our conducting practice and research, we explore how this approach offers professional conductors the opportunity to work together in an inclusive and empowering learning environment. We outline our peer learning context, the learning relationship we shared, the most significant musical outcomes of such a process, and the implications for conducting pedagogy and the professional development of conductors.

\section{Introduction}

As Ralph steps up to the podium he exudes a sense of confidence. He has been doing this for many years. The noisy chatter of the room gives way to a silent hush. The musicians shuffle in their chairs and adjust their music stands on the slippery parquetry floor. He raises his arms to begin the upbeat and looks at them with a strong sense of intent. They breathe and then follow. After forty minutes of hard work, he puts down his baton and gestures towards Brydie. She has been sitting silently at the side of the rehearsal room taking notes and watching him. Without a word, she walks towards the podium. As the ensemble sees her coming they rustle their music and pull out her repertoire. She steps up to the podium and announces the next piece they will be playing. After saying a few words to make a connection with them, she raises her arms to begin the upbeat. She looks at them with a strong sense of purpose and in that fleeting moment of transition the ensemble's sound has changed. It is not better nor worse, just different. Ralph now moves to the side of the rehearsal room and begins taking notes and watching her. We meet two days later to discuss what we learnt from our shared experience, and what we will do differently next time.

As an emerging conductor in her late 20 s and an experienced conductor in his early 50 s, we made a rather unusual duo on the podium. We had left the isolation of working alone in order to share the leadership of the Young Conservatorium Wind Orchestra (YCWO) at Griffith University in 2006. Throughout the year we contributed towards rehearsals and performances with the YCWO, observed one another's work, and reflected on the learning experience through co-constructed interviews, analysis of video footage, reflective journals, informal meetings, and focus group interviews and questionnaires with our students. We shared countless poignant musical discoveries and reflected on many philosophical issues, sometimes seeing eye to eye and other times exchanging differing opinions. What resulted 
was a profoundly moving experience, both musically and personally. It not only fuelled our desire to learn from one another and our students, but also enriched the ways in which we engaged with the music-making process as conductors.

On a number of levels, the peer learning partnership we shared was very unusual for our profession. Conducting pedagogy and professional development programs still seem to rely primarily on traditional didactic models, which encourage the one-way flow of knowledge and advice from an expert to their protégés. The disadvantage of this master-apprentice system is that it does not necessarily result in a shared, dynamic process, and tends to be somewhat limited by its inherent power issues. It also seems to draw on somewhat outdated learning models that typify a sense of cultural elitism, and lack an understanding of more informal learning environments outside the Western Conservatoire model. Our research has shown that peer learning proposes a strong alternative to such traditional models, and offers conductors a more cooperative and collaborative approach to their professional development and learning. Indeed, peer learning on the podium gives conductors the opportunity to teach and learn from each other, in an inclusive manner, that provides a musical experience qualitatively different from the didactic model of master and protégé. As we have found, it also combats the isolation conductors often experience in their work, and allows them to focus on context-specific issues together, instead of grappling with them on their own. In fact, the relationship that peers develop through such a process also offers conductors enduring support systems in their life-long professional development.

This paper has directly grown out of our peer-learning project with the YCWO, the premier symphonic wind ensemble at the Young Conservatorium, comprising students aged 11-18 years. It draws on current educational theory on peer learning and weaves this together with material from our co-constructed interviews, informal discussions, reflective journal entries and comments from our students. In the paper we outline the peer learning context, the learning relationship we have shared and the most noteworthy musical outcomes of such a process. We conclude with a brief discussion on the implications of such a learning approach for conducting pedagogy and the professional development of conductors. We do not aim to give a conclusive account of all of the musical accomplishments and challenges we faced as part of the project, but rather to give a glimpse into our learning process and the potential for further applications of this process on the podium.

\section{The peer learning context}

Prior to starting this project, we both had worked independently as conductors of various ensembles (both nationally and internationally). Ralph had been conducting for 33 years, having directed musicals, operettas, studio recordings for radio, television and disc, and the concert stage. Brydie, on the other hand, had been conducting for 8 years, having directed primary school, university and community bands.

We originally came together in the context of the YCWO in an effort to assist Brydie in her professional development. The original idea was that we would work in a mentoring relationship. However, as we began to explore the somewhat novel concept of sharing the podium we began to develop a much more reciprocal learning experience that involved both of us learning from and with each other and the ensemble. As we shared our knowledge, ideas and experiences with one another, we found the process 
not only challenged and extended our own practice, but also the ensemble's development as a whole. We found ourselves not only having to explain what we were doing and why we were doing it, but also accommodating the views expressed by each other. This was something we found a challenge at times, particularly when we experimented with switching repertoire and taking over one another's works. Although our project centred on the immediate task of directing the ensemble, and facilitating a meaningful learning experience for our students, as time went on we gave more and more explicit attention to researching and understanding this shared learning approach.

From a methodological perspective, our research was grounded in qualitative methods that helped us to explore the subjective learning experience. Following recent moves towards self-reflexive research in music education, and indeed the social sciences and humanities more broadly, these qualitative methods allowed us to critique our own positionality as conductors through our active involvement, engagement, and embodied participation in the learning process (see Spry, 2001: 710; Ellis \& Bochner, 2006: 434). Such qualitative methods involved observational research, where we closely watched one another during rehearsals and performances, and jotted down notes about the other's technique, interpretations and interactions with the ensemble. We would often get together in informal meetings after these rehearsals to discuss our observations and reflect upon a range of other personal and professional issues relating to our practice. We also undertook formal co-constructed interviews with one another, in an approach described by Ellis and Berger in their chapter, 'Their story/my story/our story' (2002). As opposed to traditional modes of interviewing, these co-constructed interviews entailed simultaneously interviewing one another and jointly constructing accounts of our learning experience. These interviews were also 'semi-structured' in nature, where we had a list of questions we wanted to ask one another, but allowed the conversation to determine how the information was obtained (see Levesque-Lopman, 2002). The interviews were recorded and later transcribed. We also kept reflective journals and used these to document and consider what we had learnt through the process. Of course, the self-questioning that these methods demanded was extremely difficult at times, as Ellis (2004) explains, 'Often you confront things about yourself that are less than flattering [...] honest autoethnographic exploration generates a lot of fears and self-doubts - and emotional pain' (xviii). However, as we explain in this paper, the benefits of engaging in such methods far outweighed the challenges and difficulties they engendered.

In addition, we asked our students to be part of these discussions through informal feedback and a focus group interview with five male and female students from different sections in the ensemble. Questions focused on what they enjoy or do not enjoy about playing in the YCWO, how the YCWO is like or unlike any of the other ensembles they play in, how they would describe our approach to conducting, what the process of working with two conductors was like, the nature of our relationships with the ensemble, and how we could improve our practice. This focus group was facilitated by one of our music education colleagues, to allow our students' anonymity, and the recording of this discussion was independently transcribed. We also carried out an anonymous questionnaire with the ensemble, which yielded 17 responses from a possible 43. This questionnaire was constructed around key issues that we had been exploring in our own reflections and discussions. These included repertoire choice, qualities of 'good' conducting, the benefits 
and challenges of working with two conductors, the similarities and differences between our approaches on the podium, the nature of our relationships with the ensemble, and areas which could be improved upon. While the focus of this particular paper is on our peer learning project as professional conductors, we should acknowledge that our students' input definitely aided our understanding of the processes involved in this learning approach. Indeed, we learnt many lessons from the ensemble, both in their responses to our research and in their musical development. They reinforced the importance of seeing this peer-learning context as a vibrant and multidimensional space, with significant relational dynamics between all involved.

\section{The peer learning relationship}

Throughout the project we placed priority on building a close rapport with one another and openly speaking about personal issues as well as professional matters. Our discussions often ranged from stories about our families to challenging professional dilemmas and contextspecific issues. Acknowledging and sharing these personal and professional aspects of our lives as learners, and then linking these to our professional practice certainly enhanced 'our capacity to know' (hooks, 1994: 148), and learn about ourselves as conductors.

We were both aware of the value of developing a trusting relationship so that our feedback could be given in an encouraging manner. Eisen (2001) identifies the importance of this in her article, 'Peer-based learning': 'Peers must believe that they are getting authentic critique and advice and they must feel that it is given in a caring, non-evaluative spirit, so that they will act on it for formative, not punitive purposes' (10). Given that we were accustomed to working fairly independently without constant evaluation from our peers, we were mindful that our feedback had to be sensitive to where the other person was situated in terms of their personal and musical growth.

This sense of building trust and relationship also extended to our musicians, and their own development. When asked whether we succeeded with this, one of our students made the following comment:

It's obvious the conductors value our contribution; we are praised for our efforts, treated with respect and listened to. Being asked to complete this questionnaire shows just how much they value our contribution because they want to know how they help us and how they can help us to be even better (Questionnaire response, Female student, 15-16 years, upper winds, 13 June 2006).

In terms of building this productive peer learning experience, we were also mindful that our differences in age, experience and skill sets could lead us to fall into a more traditional master-apprentice relationship at times. Brydie identified the importance of looking beyond such traditional relationships in her first journal entry:

So how do we begin this process? Well, I am young and in need of a technical overhaul, so this seems like a logical, and dare I say comfortable, place to start. I think this is what Ralph has in mind. I suppose it would allow us to engage with the 'bread and butter' of what we do on the podium. Ralph assists me to see what I am doing, and in turn re-examines his own practice. Having said this, I sense the potential for another aspect to this project, something that might take the shape of a concurrent philosophical 
discussion between the two of us. This might become an opportunity for us to come to the table with our own observations and experiences, and think about each other's positions and, in turn, the nature of our role in new ways. I am sure we will find many common connecting points, as well as places of divergence. In this process I hope we can learn from one another (Reflective journal entry, 18 February 2006).

While the dynamics of our work together did come unavoidably close to slipping into a more didactic model at times, our reflections and feedback never simply flowed in one direction. Although Ralph's extensive and varied conducting experience meant that he could bring a plethora of skills and suggestions to the project, Brydie's experiences as a young woman conductor also brought new and fresh perspectives on issues that are often overlooked by the conducting profession. In light of this, we came to appreciate that despite our differences in skills and experience, we did, in fact, share a somewhat surprisingly equal relationship. Such a realisation is reiterated by Eisen (2001): 'Trusting a peer as an equal requires acceptance of the 'internal expert' in each other. It also requires each person to recognise there are times to play the expert/helper role and times to ask for and receive expertise/help' (10). This is highlighted in Ralph's journal entry:

The whole situation is an obvious learning environment for her but I have found it becoming more and more one for me - a wonderful and liberating one! [...] This is a project of peers, of competent professionals who are making their work place their laboratory and their hearts their note pads. There are certain matters which are mentor and mentored but they are not all one way! (Reflective journal entry, 31 July 2006).

On closer reflection we came to realise that our dynamic and two-way interactions were the result of a common desire to serve our musicians. Our primary concerns were not self-interested or centred on our own individual career development, but rather on creating a shared vision for the ensemble and commitment to the collective music-making process. While this shared vision was specific to the context we were working in, we believe the fundamental musical outcomes which resulted from this vision would be achievable in any number of other music learning contexts.

\section{Musical outcomes of the peer learning process}

This process of sharing a common situation and collaboratively working together has been a powerful stimulus to learning. By engaging in discussions with one another we found new ways of thinking about conducting, and by observing one another we found fresh ways of reflecting on our own practice. This led to a number of learning outcomes that centred on exchanging feedback and knowledge, observing and reflecting, vision sharing, assumption breaking, and experimenting in our work with the YCWO (see Høyrup \& Elkjaer, 2006: 37). In the following discussion we highlight some of the benefits and challenges associated with some of these learning outcomes.

Peer learning through feedback and sharing knowledge

Throughout our project we found that giving feedback to one another was an essential way of thinking and learning about the consequences of our actions as conductors. Indeed, we 
found that personal feedback was 'a principal means of expanding our thinking and gaining new perspectives' (see Eisen, 2001: 10). During our project, sometimes this feedback was highly directed, as is evidenced in the following journal entry from Ralph in relation to Brydie's conducting of On a Hymn Song of Philip Bliss by David Holsinger:

Reinforce the quaver at the end of the phrase. It is 'my' from 'Well with my soul' so it is a very important note. There were times when you displayed this in a more distinct manner in the beat - beat four was more precisely enunciated - and the result was a more distinct articulation of that quaver BUT it could be reinforced to them about where they place it. Have you thought about how to help them place that quaver more effectively?' (Reflective journal entry, 28 April 2006).

Such feedback led Brydie to reassess not only her attention to that one particular quaver, but her whole approach to studying the inner parts of a score. Her acknowledgement of this is evidenced in the following conversation during our co-constructed interview:

Brydie: There are things that I still want to work on more that I know I've learnt from this last semester and still haven't got right yet; that is, the end of phrases. The biggest thing for me is having the patience to look for the inner parts, such as the quaver in Hymn Song that you gave me feedback on. I'm often too gung-ho and too impatient to look for such fine details.

Ralph: That's fantastic because you're absolutely right. That's absolutely right.

Brydie: I think that'Il probably take me another ten years, to be honest, before I get that right.

Ralph: Try twenty-five (Co-constructed interview, 26 June 2006).

At other times the feedback centred on how the students were reacting towards the other conductor. This was played out in the following piece of feedback Brydie gave to Ralph after she had a rehearsal with the ensemble on her own: 'When I was alone with the YCWO ensemble last week the change in rehearsal dynamics, interaction and sound was palpable. They played so much louder (in fact, too loud at times) and with such a different tone. When I asked them why (forgive me for saying this), they told me it was because they weren't scared' (Reflective journal entry, 22 March 2006). In the months that followed Brydie's feedback, she could see that Ralph had taken this to heart and acknowledged its significance in terms of building a more open and trusting relationship with the ensemble. He confirmed this by saying:

When you spoke to me about a third of the way through the semester and talked to me about the fear they had, once upon a time I would have been offended by that. Now I'm concerned for that. I know I get very intense and that manifests in a physical presence, and I know that I try to mitigate that with the light heartedness I come up with, the mad humour ... I'm conscious of my intimidating presence. I'm not afraid to use intimidation, but I also don't want to marginalise anybody by it (Co-constructed interview, 26 June 2006).

Høyrup and Elkjaer (2006) suggest that sharing knowledge through feedback such as this 'can be seen as a dimension of non-defensive behaviour, promoting learning' (37). Indeed, 
sharing such knowledge means that people are not only motivated by protecting their own position but want to be part of something bigger than themselves (Senge cited in Høyrup \& Elkjaer, 2006: 37). Feedback, like we gave one another, leads to a collective process where 'reflection brings to the surface - in the safe presence of trusting peers - the social, political and emotional data that arise from direct experience with one another' (Raeline cited in Høyrup \& Elkjaer, 2006: 36).

\section{Peer learning through observation and reflection}

Through our observations of one another, our reviewing of video footage from rehearsals and our reflective journals we were continually reminded of the areas in our practice that needed improvement. Unlike the situation of working alone, where many things can easily go unnoticed, we found ourselves personally reflecting on our own practice and questioning our practice in relation to our observations of one another and the ensemble. As Høyrup and Elkjaer (2006) identify, 'Reflection makes it possible to interpret faults as sources for improvement or learning' (37). At times this meant treating our ensemble as a 'mirror' of our practice, and reflecting on what they were 'telling' us through their playing, and where we needed to improve our work. Through this process we became more sensitive to the process of building connections with our YCWO students, and communicating our shared desires for the ensemble in comparable ways.

Further observations and reflections on our shared work on the podium also brought into stark contrast a number of other related issues. We came to realise that neither of us could assume an independent relationship with the musicians; we had to constantly be mindful and respectful of the other person. This became apparent when we asked our students to describe our approaches in a questionnaire. Their observations were not based on us as single entities but rather in relation to one another and the repertoire we were conducting at the time:

Ralph has a very eccentric and energetic approach, while Brydie has a more calm although still energetic approach I feel (Questionnaire response, Male student, 15-16 years, percussion, 13 June 2006).

They expect the same thing, but Ralph goes for a more 'fear' approach where Brydie seems more relaxed, however none raise their voice unless we deserve it (Questionnaire response, Female student, 15-16 years, upper winds, 13 June 2006).

Ralph is funny, powerful yet forceful. Brydie is calm, demanding, patient, soft and really good at expressing the piece (Questionnaire response, Female student, 15-16 years, upper winds, 13 June 2006).

Ralph is very forceful in his ways whereas Brydie is more 'quiet' and more reserved (Questionnaire response, Female student, 15-16 years, upper winds, 13 June 2006).

Brydie focuses on emotion, while Ralph likes to drill on techniques, but sometimes they share these qualities (Questionnaire response, Female student, 17-18 years, upper winds, 13 June 2006). 
I believe that one prefers more sensitive music while the other prefers more powerful music (Questionnaire response, Male student, 15-16 years, lower brass, 13 June 2006).

Such evaluations point towards our students' observations of our personality traits and different characteristics on the podium and in some ways reflect somewhat accurate portrayals of us as conductors and people. In others, they glaringly point towards how we have both been perceived in terms of the other; that is, the young 'quiet, relaxed, and expressive' woman conductor and the experienced 'forceful, eccentric and powerful' male conductor. Such stereotypically gendered impressions seemed to invoke old and lingering dualisms, such as man/woman, relaxed/forceful, emotional/technical, which were heightened by the repertoire we were conducting. At the time of the questionnaire Ralph was focusing on his somewhat powerful work, Whirr, Whirr, Whirr and Brydie was focusing on Aaron Copland's more gentle work, Down a Country Lane. Indeed, as Brydie has argued elsewhere, dualisms, such as those mentioned by our students, are deeply ingrained with gendered power relations that often translate into stereotypical social ideas about the conductor' and their relationship to the repertoire (Bartleet, 2002, 2003, 2004, 2005, 2006). Given the ways in which the students' observations were comparing us in such stereotypically gendered terms, we had to reflect on ways to combat the notion that Ralph was the more dominant and powerful male conductor and Brydie was the more sensitive and emotive female conductor. Hence by working in this shared context such attitudes, which would customarily be left silent and un-critiqued, were exposed and demanded reflection not only from us but also our students.

\section{Peer learning through sharing a vision}

Despite our different conducting personas on the podium, we still sought to express a shared vision for the ensemble. The formulation of this vision - which occurred through many discussions that challenged us to coherently express our ideas and concepts to one another - formed a key part of our reflective learning process (see Høyrup \& Elkjaer, 2006: 37). We both agreed that our vision needed to be strongly focused on the young people we were working with, and needed to be driven by our genuine concern for them. Indeed, in our shared vision we both wanted to address what we perceived to be a lack of compassion in teaching and conducting. This is an issue which hooks (1993) also recognises in the context of university teaching: 'There is not much passionate teaching or learning taking place in higher education today. Even when students are desperately yearning to be touched by knowledge, professors still fear the challenge, allow their worries about losing control to override their desires to teach' (62-63). In line with this, Ralph made the following comment in our co-constructed interview:

Our philosophy is the same. It's a terrible cliché, I don't teach music, I teach humans, I teach people but it is a truism and too many people forget about that. They're content driven and they've got to know $X, Y$ and $Z$, but what they really need to be put in is a situation where they can discover $\mathrm{X}, \mathrm{Y}$ and $\mathrm{Z}$, not unclip the head and pour it in and stir and clip the head back down. I mean, unclip the heart and let it in. That's a different thing (Co-constructed interview, 26 June 2006). 
Brydie expresses similar sentiments to Ralph's analogy - of opening the heart to discover music, rather than passively filling the head with information - in the following comment from our co-constructed interview: 'I not only want to teach music to them, but also experience humanity with them. I want to be present as a conductor. I want to be involved with my musicians as a conductor. I want to love them as a conductor. Love is a very big one for me. I want to learn with them. I want to be the loving compassionate person that I aim to be in life on the podium as well' (Co-constructed interview, 26 June 2006). However, in saying that, Brydie is mindful of what hooks (1993) says about the context of university teaching:

Well-learned distinctions between public and private make us believe that love has no place in the classroom. Professors are expected to publish but no one really expects or demands of us that we really care about teaching in uniquely passionate and different ways. Teachers who love students and are loved by them are still 'suspect' in the academy. Some of the suspicion is that the presence of feelings, of passions, may not allow for objective consideration of each student's merit. But this very notion is based on the false assumption that education is neutral, that there is some 'even' emotional ground we stand on that enables us to treat everyone equally dispassionately (62).

Despite such obstacles and scepticism, which we believe to a certain extent also pervade the conducting profession, we were convinced that both compassion and love were key elements in realising our shared musical vision with the ensemble. This did not go unnoticed by our musicians and allowed both of us to develop close bonds with individual students and the ensemble as a whole. As one of our students said in the focus group: 'A lot of what they talk about the music can apply to life [... I I think that they do show that they do care about the people [... ]' (Focus group response, 15 June 2006). Another student commented: 'They have respect for us as musicians, and with that bring expectations that we give our best as they do' (Questionnaire response, Female student, 17-18 years, upper winds, 13 June 2006).

\section{Peer learning through breaking assumptions}

Our work together - as co-conductors rather than master-apprentice conductors - certainly brought into question a number of assumptions and norms from our profession. It was by no means an easy task navigating through them; in fact, we often found ourselves wading through unknown and uncharted territory. Indeed, breaking assumptions has been described as one of the most arduous steps in the learning and reflective process, because identifying and questioning assumptions goes against the organisational grain (Høyrup \& Elkjaer, 2006: 36). This process opens up our plans and actions to scrutiny, as we subject our assumptions to the review of others (Raeline cited in Høyrup \& Elkjaer, 2006: 36).

This is evidenced in the following journal entry of Brydie's as she grapples with the disjuncture between the profession's 'norms' and our peer learning relationship: 'If conducting is indeed based on patriarchal ideology one would assume that the conductor has a monogamous relationship with their ensemble. What does that mean for us? Is there room for two of us?' (Reflective journal entry, 3 June 2006). We have both had to break 
through a number of assumptions of our profession, which indicate that conductors need to work as autonomous individuals (see Schuller, 1997). Having said this, by our challenging of the traditionally autonomous role, many of our students came to realise the benefits of such a process:

I really like having two conductors actually, because instead of having someone for, what is it, an hour and a half, you're getting different viewpoints on the all the same material, seven different pieces, so I feel the conductors work together to give us a bit more knowledge (Focus group response, 15 June 2006).

I enjoy working with two conductors because you get more variety in pieces and you get more advice and different opinions on different things. As well as this, each conductor has their own unique ideas (Questionnaire response, male student, 1718 years, lower winds, 13 June 2006).

I enjoy having two conductors who each bring their own strengths to the group and help us to be the best we can be and motivate us (Questionnaire response, female student, 17-18 years, upper winds, 13 June 2006).

In our informal discussions and co-constructed interviews, we also challenged a number of other personal and professional assumptions that ranged from practical issues of score study to more philosophical debates of religious symbolism on the podium. While working closely together through this process has highlighted our similarities, it has also emphasised 'the importance of understanding and working with the idea of difference' (Sampson \& Cohen, 2001: 26). Reflecting on and understanding our different assumptions and beliefs certainly informed and affected our actions on the podium.

\section{Peer learning through experimentation}

Throughout this process we also found that it was important to not only talk about particular ideas relating to our work, but also experiment with them in new practical ways. On one occasion, we decided to swap repertoire in the middle of the term, and take over a piece that the other conductor had been working on. This was fuelled by our desire to further explore the dynamics of a conductor's relationship towards the repertoire they are conducting. We discovered that this 'experiment' was a tricky task that was fraught with issues that needed to be approached with sensitivity. This is evidenced in the following observations as Brydie watched Ralph take over 'her' piece, Greensleeves Fantasie by Anne McGinty:

When you said your tempo was right, (i.e. right when you're on the podium) you are challenging my interpretation and they know it! Ouch. I'm keeping my eyes down trying to avoid their gaze. [...] Now they're playing for you and it will become yours. Why am I reacting this way? Is it because I've been taught to develop a sense of ownership, i.e. authorship over a piece? You keep criticising how they're playing, but you're also criticising my interpretation of it; for example, 'you're playing it like an etude and not a courtly march.' Does this make me lose face? I know it's for the music's sake. I don't have a right to claim ownership over this, do I? (Reflective journal written during rehearsal, 19 August 2006) 
Over the following months, Brydie watched Ralph make this work his own, and learnt many lessons through his interpretation and rehearsal of it. She came to see the danger in her original possessiveness, which was ultimately fuelled by personal insecurity, and how this was largely a product of her training.

This situation was played out in a different manner when Brydie took over one of Ralph's pieces, Jessie's Well. This was not only a piece that Ralph had been working on with the ensemble, but also a work he had composed. Given the delicate issues of 'authorship' and 'ownership' that were at the fore, Brydie started the process of rehearsing Jessie's Well with great trepidation. She feared that she might disappoint Ralph with her interpretation; she feared how the students would react to her interpretation; but most of all she feared she might not do the piece justice. The ensemble's restrained sound seemed to indicate that they were also experiencing great uncertainty about this experiment. In reaction to this situation, Ralph wrote the following remark: 'She seemed like the stepmother doing Jessie's! She was unsure, they played like she was intruding on their patch [...] Jessie was my baby!' (Reflective journal, 31 July 2006). So in an effort to allay Brydie's fears Ralph shared copies of the original sketches and his personal journals about the creation of the work. After this Ralph noticed a distinct change in Brydie's attitude towards interpreting the work and gave her this feedback in his observational notes:

After some time she told them that I had shared my closest secrets about Jessie's creation and as I sat writing notes, listening to that explanation she began to play the piece and it was as if it was a different group. Suddenly they played for her. She was now no longer the wicked stepmother but someone else. She was my trusted friend so they allowed her to play Jessie and to do so with them. It was a truly amazing moment! [...]

You began afraid - maybe me in the room, maybe lack of confidence, maybe their timidity was reflected in you. Doesn't matter now - they're yours; the piece is becoming yours too! It's your painting now - you colour it (Reflective journal entry, 31 July 2006).

Reaching this point of trust, between both of us and the ensemble, was a long process that was certainly aided by our peer learning project. By having such a close and open partnership on the podium, and sharing the commitment of guiding our musicians in this experience, we were able to experiment and work through a number of complex problems that were associated with building a connection between ourselves and the ensemble. This is shown in Brydie's recollections of performing the piece with the ensemble for the first time:

It wasn't the most refined of performances, but it certainly had something magical about it. I wanted to make this performance special. I wanted it to be like a gift to Ralph to say thank you for this amazing journey. I suspect the students felt the same way. I don't recollect conducting much during the performance; I remember holding my arms close to my chest and heart. I don't recollect looking at the score much either. If the truth were told, it wasn't the score that led me to feeling the strong emotions I felt towards this piece. The score was merely a vehicle (that dare I say got in the way at times). My knowing Ralph was what made me connect with it in a way that I hadn't connected with many other works before. At the end of the performance, when I turned around to take a bow, I looked at Ralph sitting in the audience and I think I saw 
a tear in his eye. I hope that means he liked it (Reflective journal entry, 9 September 2006).

\section{Conclusions}

As we have reflected on the project and sifted through our rich research materials, we have come to appreciate how the project engaged us as active learners on the podium. Working together not only enriched our own learning development, and resulted in a close collegial bond, but also deepened the musical experiences of our students. Given the benefits of such a holistic learning process, we believe there is a need for future research to address how such peer learning partnerships could be integrated into conducting pedagogy at the university level (and indeed, the professional development of conductors of all stages). Moreover, such research could also examine wider applications of this process in areas closely related to conducting, such as instrumental and choral music pedagogy.

As we have illustrated, the establishment of such a process would firstly involve conductors identifying a situation which would lend itself to a peer learning project. This would need to include willing learners and a music-making context that occurs on a regular basis, so that these collaborative relationships could be developed and experimented with over time. For instance, conducting students are often involved as musicians in conducting classes, forming the ensemble that students conduct, so the scope for pairing peers or including peer assessment is worthy of consideration. Closer to our particular project at the professional level, such partnerships could also be set up with colleagues working in close proximity to one another in school or community contexts (see Boud, 1999; Boud \& Middleton, 2003; Cressey et al., 2006). There is also the possibility of drawing upon support structures and professional bodies that organise mentoring systems or professional development programs and using their resources for arranging such partnerships. Secondly, setting up this process would also entail conductors negotiating a structure for the peer learning process that is conducive to sharing and exchanging musical ideas and outcomes. While our paper has detailed one example of how this process could be organised, there is a wealth of literature on how other peer learning projects have been structured in other settings (see King, 1990; Petonito, 1991; Anderson \& Boud, 1996; Blumenfeld et al., 1996; Slavin, 1996; Tosey \& Gregory, 1998; Cox, 1999; Boud et al., 2001). Thirdly, developing this process would also involve conductors devising a framework for reflecting, reviewing, and in the case of students, assessing, the collaborative process (see Sluijsmans et al., 1999; Blom \& Poole, 2004; Hunter 2006). We found our combination of reflective tools - including observations of one another's work, co-constructed interviews, analysis of video footage, reflective journals, informal meetings, and focus group interviews and questionnaires with our students - not only contributed to our learning processes and enhanced the project, but also allowed us to monitor and adapt to the ever-changing and evolving dynamics of our peer learning relationship.

We are, however, mindful that the broader application of this approach may engender resistance (both individual and institutional) from the conducting profession. Such resistance might stem from lingering pedagogical traditions, reluctance from conductors to share or partly give up their situational status, fear that revealing one's weaknesses to colleagues might be detrimental to one's employment prospects, and concerns about the 
extra organisation effort required to set up such projects. These are valid and reasonable concerns; however, as we have suggested in this paper, the benefits of such an approach far outweigh such challenges. More specifically, we believe peer-learning projects have the potential to significantly assist in the development of conductors' skill bases, relationships with ensembles, collaborative and teamwork abilities, critical enquiry and reflective skills, and are worthy of further research and practical application.

\section{Note}

A video exemplar offering supplementary viewing of data will be made available on the BJME homepage: journals.cambridge.org/bjme.

\section{References}

ANDERSON, G. \& BOUD, D. (1996) 'Extending the role of peer learning in university courses', Research and Development in Higher Education 19: 15-19.

BARTLEET, B. L. (2002) 'Re-embodying the 'gendered podium', Context: Journal of Music Research 23: 39-47.

BARTLEET, B. L. (2003) 'Female conductors: The incarnation of power?', Hecate: An Interdisciplinary Journal of Women's Liberation 29 (2): 228-34.

BARTLEET, B. L. (2004) 'From coffee houses to executive suites: an experiential approach to feminist musicology', in J. Phillips, M. Ewans, R. Halton \& L. Barwick (Eds), Music Research: New Directions For a New Century (pp. 186-95). London: Cambridge Scholars Press.

BARTLEET, B. L. (2005) 'Reflections on females conducting', in E. Mackinlay, D. Collins \& S. Owens (Eds), Aesthetics and Experience in Music Performance (pp. 235-42). London: Cambridge Scholars Press.

BARTLEET, B. L. (2006) 'Conducting motherhood: The personal and professional experiences of women orchestral conductors', Outskirts: Feminisms along the Edge, 15. Available at http:// www.chloe.uwa.edu.au/outskirts

BLOM, D. \& POOLE, K. (2004) 'Peer assessment of tertiary music performance: Opportunities for understanding performance assessment and performing through experience and self-reflection', British Journal of Music Education 24 (1): 111-25.

BLUMENFELD, P. C., MARX, R. W., SOLOWAY, E. \& KRAJCIK, J. (1996) 'Learning with peers: From small group cooperation to collaborative communities', Educational Researcher 25 (8): 37-40.

BOUD, D. (1999) 'Situating academic development in professional work: using peer learning', International Journal for Academic Development 4 (1): 3-10.

BOUD, D. \& MIDDLETON, H. (2003) 'Learning from others at work: communities of practice and informal learning', Journal of Workplace Learning 15 (5): 194-202.

BOUD, D., COHEN, R. \& SAMPSON, J. (2001) Peer Learning in Higher Education: Learning From and With Each Other. London: Kogan Page.

COX, M. D. (1999) 'Peer consultation and faculty learning communities', New Directions for Teaching and Learning 79: 39-49.

CRESSEY, P., BOUD, D. \& DOCHERTY, P. (2006) 'The emergence of productive reflection', in D. Boud, P. Cressey \& P. Docherty (Eds), Productive Reflection at Work: Learning for Changing Organizations (pp. 11-26). London: Routledge.

ELLIS, C. (2004). The Ethnographic l: A Methodological Novel about Autoethnography. Walnut Creek, CA: AltaMira Press. 
ELLIS, C. \& BERGER, L. (2002) 'Their story/my story/our story: Including the researcher's experience in interview research', in J. F. Gubrium \& J. A. Holstein (Eds), Handbook of Interview Research: Context and Method (pp. 849-75). Thousand Oaks, CA: Sage.

ELLIS, C. \& BOCHNER, A. (2006) 'Analyzing analytic autoethnography: an autopsy', Journal of Contemporary Ethnography 35 (4): 429-49.

EISEN, M. J. (2001) 'Peer-based learning: A new-old alternative to professional development', Adult Learning 12 (1): 9-10.

HOOKS, B. (1994) Teaching to Transgress: Education as the Practice of Freedom. New York: Routledge.

HOOKS, B. (1993) 'Eros, eroticism and the pedagogical process', Cultural Studies 7 (1): 58-63.

HØYRUP, S. \& ELKJAER, B. (2006) 'Reflection: Taking it beyond the individual', in D. Boud, P. Cressey \& P. Docherty (Eds), Productive Reflection at Work: Learning for Changing Organizations (pp. 29-42). London: Routledge.

HUNTER, D. (2006) 'Assessing collaborative learning', British Journal of Music Education 23 (1): 75-89.

KING, A. (1990) 'Enhancing peer interaction and learning in the classroom through reciprocal questioning', American Educational Research Journal 27 (4): 664-87.

LEVESQUE-LOPMAN, L. (2000). 'Listen and you will hear: Reflections on interviewing from a feminist phenomenological perspective', in L. Fisher (Ed.), Feminist Phenomenology (pp. 103-32). Dordrecht: Kluwer Academic Publishers.

PETONITO, G. (1991) 'Fostering peer learning in the college classroom', Teaching Sociology 19 (4): 498501.

SAMPSON, J. \& COHEN, R. (2001) 'Designing peer learning', in D. Boud, R. Cohen \& J. Sampson (Eds), Peer Learning in Higher Education: Learning From and With Each Other (pp. 21-34). London: Kogan Page.

SCHULLER, G. (1997) The Compleat Conductor. New York: Oxford University Press.

SLAVIN, R. E. (1996) 'Research on cooperative learning and achievement: what we know, what we need to know', Contemporary Educational Psychology 21: 43-69.

SLUIJSMANS, D., DOCHY, F. \& MOERKERKE, G. (1999) 'Creating a learning environment by using self-, peer- and co-assessment', Learning Environments Research 1: 293-319.

SPRY, T. (2001) 'Performing autoethnography: An embodied methodological praxis', Journal of Contemporary Ethnography 7 (6): 706-32.

TOSEY, P. \& GREGORY, J. (1998) 'The peer-learning community in higher education: reflections on practice', Innovations in Education and Training International 35 (1): 74-81. 